\title{
Progesterone-synthesizing ability of preovulatory follicles of cows relative to the peak of $\mathrm{LH}$
}

\author{
S. J. Dieleman and D. M. Blankenstein \\ Clinic for Veterinary Obstetrics, A.I. \& Reproduction, State University of Utrecht, Yalelaan 7, De Uithof, \\ 3508 TD Utrecht, The Netherlands
}

\begin{abstract}
Summary. Preovulatory cow follicles $(n=34)$ were collected at different times after the onset of oestrus until shortly before ovulation. In-vitro conversion of tritiated pregnenolone in the presence of $\mathrm{NAD}^{+}$by homogenates of the follicular wall was compared in phases relative to the LH peak. During phase 0 (before the LH surge) a moderate conversion into progesterone occurred, but it was subsidiary to that into $17 \alpha$-hydroxypregnenolone and other unidentified steroids. During phases $1(0-6 \mathrm{~h}$ after the $\mathrm{LH}$ peak), $2 \mathrm{~A}(6-14 \mathrm{~h})$ and $2 \mathrm{~B}(14-20 \mathrm{~h})$ the production of progesterone and $17 \alpha$-hydroxypregnenolone remained constant; at phase $2 \mathrm{~B}$ the percentage of remaining pregnenolone was higher than in the preceding phases. In phase 3 ( $20 \mathrm{~h}$ after the $\mathrm{LH}$ peak until ovulation) conversion into progesterone had increased about 4 -fold to the highest levels observed ( $97 \%$ after $2 \mathrm{~h}$ incubation), and production of $17 \alpha$-hydroxypregnenolone and unidentified steroids was low. In an additional experiment, homogenates of the wall of 3 follicles at phase 3 were also incubated with tritated progesterone in the presence of NADPH. The percentage of remaining progesterone was high, and a moderate conversion into $17 \alpha$-hydroxyprogesterone occurred. In the main experiments, however, production of this steroid was not observed.

The results indicate that steroid synthesis in the preovulatory follicle of the cow changes to the production of progesterone shortly before ovulation.
\end{abstract}

\section{Introduction}

After ovulation, differentiation of the cells of the follicular wall into luteal cells, which constitute the corpus luteum producing progesterone, appears to be initiated by luteinizing hormone (LH) (see Fritz \& Speroff, 1982, for review). In several mammalian species a sometimes transitory increase of the progesterone concentration in the follicular fluid is observed before ovulation (man: McNatty, Hunter, McNeilly \& Sawers, 1975; rat: Szoltys, 1976: pig: Ainsworth, Tsang, Downey, Marcus \& Armstrong, 1980; sheep: Murdoch \& Dunn, 1982), which is considered to be a sign of the onset of functional luteinization. In the cow, a sharp increase of the progesterone concentration in the fluid of preovulatory follicles takes place shortly before ovulation during phase 3 of the preovulatory development (Dieleman, Kruip, Fontijne, de Jong \& van der Weyden, 1983b). A preliminary experiment (S. J. Dieleman \& Th. A. M. Kruip, unpublished observations) indicated a rapid conversion of pregnenolone into progesterone in the presence of $\mathrm{NAD}^{+}$shortly before ovulation.

In the present study, therefore, we investigated whether the progesterone-synthesizing ability of preovulatory cow follicles increases at about $20 \mathrm{~h}$ after the preovulatory peak of LH. Also, possible conversion of progesterone was examined shortly before ovulation to determine whether progesterone is an end-product at this stage of follicular development. 


\section{Materials and Methods}

Collection of follicles. Preovulatory follicles from Dutch-Friesian heifers $(n=34)$ with normal cycles were collected at known times after the onset of oestrus until ovulation (Dieleman et al., 1983b; Dieleman, Bevers, Poortman \& van Tol, 1983a). Blood samples for the radioimmunoassay (RIA) of LH were collected at hourly intervals from the time of luteal regression, as determined by estimating the progesterone concentration in the peripheral blood, twice a day with a rapid RIA, until at least $24 \mathrm{~h}$ after onset of oestrus. Immediately after recovery of the ovaries by ovariectomy the largest follicle, being preovulatory (Dufour, Whitmore, Ginther \& Casida, 1972), was dissected free of stromal tissue and its diameter was measured under a stereomicroscope as described by Kruip \& Dieleman (1982). On the basis of histological examination of a small piece of the follicular wall, the follicles used were identified as non-atretic (Dieleman et al., 1983b).

Chemicals. When not specified, chemicals were of analytical reagent grade and obtained from Merck AG, Darmstadt, West Germany; organic solvents were distilled just before use. [7(n) $\left.{ }^{3} \mathrm{H}\right]$ Pregnenolone (sp. act. $0 \cdot 370 \mathrm{PBq} / \mathrm{mol}$; tritium distribution over positions $7 \alpha, 7 \beta$ and $4: 52$, 28 and $20 \%$ respectively) and $\left[1,2,6,7(\mathrm{n})-{ }^{3} \mathrm{H}\right]$ progesterone (sp. act. $3 \cdot 22 \mathrm{PBq} / \mathrm{mol}$ ) were purified by thin-layer chromatography (t.l.c.; DC Fertigplatten F 254; Merck AG). These tracers and $\left[4-{ }^{14} \mathrm{C}\right]$ pregnenolone (sp. act. $2.07 \mathrm{TBq} / \mathrm{mol}$ ) and $\left[4-{ }^{14} \mathrm{C}\right]$ progesterone (sp. act. $2.07 \mathrm{TBq} / \mathrm{mol}$ ) were obtained from Amersham International Ltd, Bucks, U.K., and $\left(4-{ }^{14} \mathrm{C}\right] 17 \alpha$-hydroxyprogesterone (sp. act. $1.85 \mathrm{TBq} / \mathrm{mol}$ ) from New England Nuclear, Boston, MA, U.S.A.; the ${ }^{14} \mathrm{C}$-tracers were subjected to routine checks for purity by t.l.c. and, if necessary, purified by filtration on Sephadex LH-20 (Pharmacia Fine Chemicals, Uppsala, Sweden). Steroids were purchased from Steraloids Inc. (Wilton, NH, U.S.A.). Aqueous samples for radioactivity measurements were dispersed in a xylene-based mixture and counted as described previously (Dieleman et al., 1983b). Samples in organic solvents were dissolved in Instafluor II (Packard Instruments Company, Downers Grove, IL, U.S.A.) and counted as described previously (Dieleman \& Blankenstein, 1984).

Incubation. After dissecting the preovulatory follicles, the follicular wall was weighed and subsequently homogenized at $0^{\circ} \mathrm{C}$ in $13 \mathrm{ml}$ Tris- $\mathrm{HCl}$ buffer $(0.01 \mathrm{M}, \mathrm{pH} 7.4)$ with mannitol $(0.25 \mathrm{M})$. The mean interval from ovariectomy until homogenization was $31.8 \pm 13.4$ (s.d.) $\min (n=34)$. The homogenates were centrifuged at $900 \mathrm{~g}$ for $20 \mathrm{~min}$ at $4^{\circ} \mathrm{C}$ and the supernatant was used for incubation. The incubation mixture consisted of $0.5 \mathrm{ml}$ propyleneglycol containing about $0.158 \mathrm{MBq}\left[7(\mathrm{n})-{ }^{3} \mathrm{H}\right]$ pregnenolone and $3 \mathrm{ml}$ supernatant, to which was added $0.5 \mathrm{ml}$ of a solution of $\mathrm{NAD}^{+}$(Boehringer, Mannheim, West Germany) in Tris-HCl-mannitol buffer (final concentration of $\mathrm{NAD}^{+} 0 \cdot 2 \mathrm{~mm}$ ). The incubations were carried out under continuous shaking at $39^{\circ} \mathrm{C}$ (body temperature of the cow) in an air atmosphere. After 15, 30, 60 and $120 \mathrm{~min}, 0.9 \mathrm{ml}$ samples were pipetted from the incubation mixture and the enzyme reactions were stopped by the addition of $3 \mathrm{ml}$ dichloromethane; thereafter the fractions were stored at $-25^{\circ} \mathrm{C}$. In an additional experiment a further $3 \mathrm{ml}$ of the supernatant $(n=3)$ were incubated similarly for 120 min with about $0.343 \mathrm{MBq}\left[1,2,6,7(\mathrm{n})-{ }^{3} \mathrm{H}\right]$ progesterone in the presence of NADPH (Boehringer; final concentration of NADPH $0.2 \mathrm{~mm}$ ). Blank incubations with $3 \mathrm{ml}$ Tris-HCl-mannitol buffer instead of homogenate showed no conversion of pregnenolone after 15, 30,60 and 120 min incubation $(n=4)$ respectively.

Extraction and processing for incubations with tritiated pregnenolone. After 4-fold extraction each time with $6 \mathrm{ml}$ dichloromethane (recovery: $98.5 \pm 0.5 \%, n=136$ ), a mixture of ${ }^{14} \mathrm{C}$-labelled pregnenolone and progesterone (about 1.0 and $1.1 \mathrm{kBq}$ respectively) was added in a known proportion in $10 \mu \mathrm{l}$ for procedural recovery measurement and recrystallization purposes. Subsequently, the residues after evaporation in vacuo were subjected to t.l.c. The plates were developed 3 times in benzene:cyclohexane $(1: 1, \mathrm{v} / \mathrm{v}$; System 1$)$ to remove fatty materials, and twice in chloroform: methanol (99:1, v/v; System 2). Radioactive areas were recorded on radioscans using a thin-layer scanner (LB 2723/6280/241 K; Berthold-Frieseke, Karlsruhe, West Germany) with a sensitivity 
which permitted detection of conversion percentages of steroid $>1 \%$. Thereafter the fractions containing pregnenolone and progesterone were further purified by recrystallization up to a constant ratio of ${ }^{3} \mathrm{H} /{ }^{14} \mathrm{C}$ activities, and the area corresponding with $17 \alpha$-hydroxypregnenolone was isolated. For 5 fractions, $17 \alpha$-hydroxypregnenolone was further purified by t.l.c. (System 2) and subsequent recrystallization to constant specific activity. The conversion percentage of progesterone and the percentage of pregnenolone remaining were calculated from the ${ }^{3} \mathrm{H}$ activity of the pure steroids in proportion to the total ${ }^{3} \mathrm{H}$ activity after extraction and corrected for recovery. That of $17 \alpha$-hydroxypregnenolone was estimated by correcting the ${ }^{3} \mathrm{H}$ activity of the corresponding fraction after t.l.c. (Systems 1 and 2) for the mean recovery $(75 \cdot 8 \pm 10 \cdot 2 \%, n=8)$. The coefficient of variation due to statistical errors in measurements of radioactivity was $<4$ and $<15 \%$ for percentage conversions of $>1$ and $<0.5$ respectively.

Extraction and processing for incubations with tritiated progesterone. The extraction and purification procedures were similar to those mentioned above. The t.l.c. fraction containing $17 \alpha-$ hydroxyprogesterone was subjected again to t.l.c. (benzene:ether, $4: 1, \mathrm{v} / \mathrm{v}$; developed twice), after which 17 $\alpha$-hydroxyprogesterone was further purified by recrystallization to a constant ratio of ${ }^{3} \mathrm{H} /{ }^{14} \mathrm{C}$ activities.

Statistical analysis. The paired $t$ test (two-tailed) was used to compare the means of two samples. Differences between the means of samples in grouped data were tested for significance by analysis of variance according to Scheffé (1959).

\section{Results}

The time when the maximum LH concentration was recorded in peripheral blood was defined as the LH peak. The mean ( \pm s.d.) intervals between onset of oestrus, i.e. first standing oestrus, and the onset of the $\mathrm{LH}$ surge (first elevated concentration of $\mathrm{LH}$ followed by higher values) and between the maximum $\mathrm{LH}$ value and ovulation, have been reported previously to be $1.7 \pm 2.4$ and $24 \pm 1.4 \mathrm{~h}$ respectively (Dieleman et al., 1983b).

Before the LH surge (phase 0), 6 follicles were collected; the mean ( \pm s.e.m.) diameter and weight of the follicular wall were $16.2 \pm 0.8 \mathrm{~mm}$ and $209 \pm 27 \mathrm{mg}$ respectively. After the LH peak 27 follicles were collected: 6 at $0-6 \mathrm{~h}$ after the LH peak (phase 1; size and weight: $16 \cdot 0 \pm 1 \cdot 0 \mathrm{~mm}$ and $227 \pm 39 \mathrm{mg}$ respectively), 6 at $6-14 \mathrm{~h}$ (phase $2 \mathrm{~A} ; 15.7 \pm 0.5 \mathrm{~mm}$ and $268 \pm 44 \mathrm{mg}$ ), 5 at 14-20 $\mathrm{h}$ (phase 2B; $18.1 \pm 0.6 \mathrm{~mm}$ and $335 \pm 33 \mathrm{mg}$ ) and 10 between $20 \mathrm{~h}$ and ovulation (phase 3; $16.9 \pm 0.7 \mathrm{~mm}$ and $317 \pm 36 \mathrm{mg})$. In one heifer $(16 \mathrm{~mm}, 209 \mathrm{mg})$ ovulation had taken place shortly before ovariectomy, and the interval after the LH peak was $23 \mathrm{~h}$. The diameter of the follicles varied from 13.7 to $20 \mathrm{~mm}$ independently of the stage of preovulatory development. Analysis of variance proved the apparent increase in weight of the follicular wall to be non-significant.

Table 1. Conversion percentage of $17 \alpha$-hydroxypregnenolone and the percentage of unidentified steroid after $120 \mathrm{~min}$ incubation with $\left[7(n)-{ }^{3} \mathrm{H}\right]$ pregnenolone of homogenates of preovulatory cow follicles in the phases between onset of oestrus and ovulation

\begin{tabular}{lcccc}
\hline Phase & $\begin{array}{c}\text { Period* } \\
(\mathrm{h})\end{array}$ & $\begin{array}{c}\text { No. of } \\
\text { follicles }\end{array}$ & $\begin{array}{c}\text { 17a-Hydroxy- } \\
\text { pregnenolone }\end{array}$ & $\begin{array}{c}\text { Unidentified } \\
\text { steroid }\end{array}$ \\
\hline 0 & Before & 6 & $38 \cdot 5 \pm 3 \cdot 3$ & $33 \cdot 5 \pm 3 \cdot 5$ \\
1 & $0-6$ & 6 & $43 \cdot 1 \pm 6 \cdot 7$ & $28 \cdot 8 \pm 7 \cdot 5$ \\
2A & $6-14$ & 6 & $51 \cdot 1 \pm 4 \cdot 9$ & $28 \cdot 1 \pm 5 \cdot 5$ \\
2B & $14-20$ & 5 & $40 \cdot 3 \pm 7 \cdot 2$ & $21 \cdot 5 \pm 10 \cdot 9$ \\
3 & $20-25$ & 10 & $10 \cdot 9 \pm 3 \cdot 7$ & $8 \cdot 4 \pm 2 \cdot 4$ \\
\hline
\end{tabular}

Values are mean \pm s.e.m.

* In relation to $\mathrm{LH}$ peak level. 


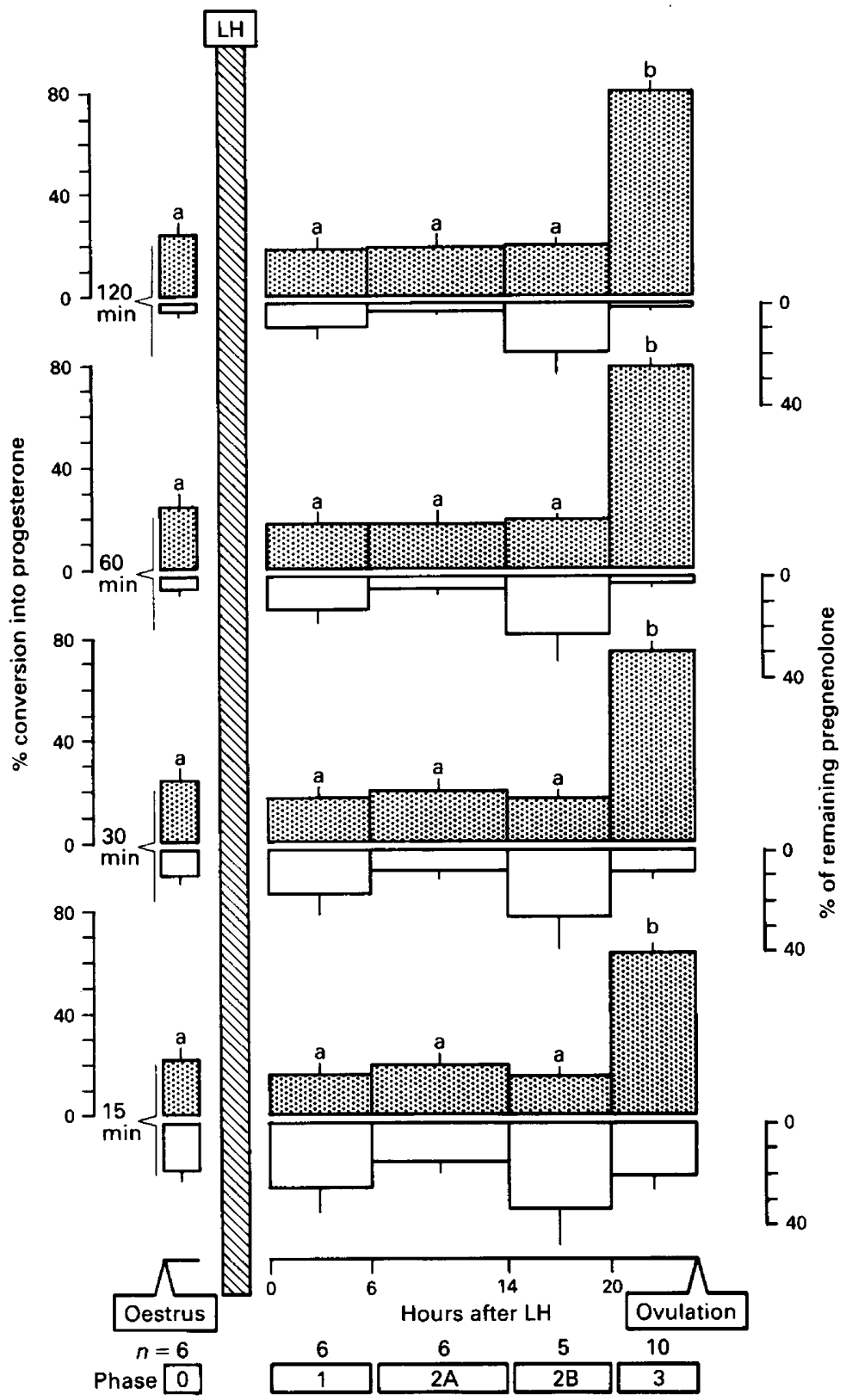

Text-fig. 1. Conversion percentage of progesterone (stippled histograms) and the percentage of remaining pregnenolone (open histograms) after incubation for $15,30,60$ and 120 min with $\left[7(n)-{ }^{3} \mathrm{H}\right]$ pregnenolone of homogenates of preovulatory cow follicles in the phases between onset of oestrus and ovulation. Values are mean \pm s.e.m. for the no. of follicles indicated $(n)$. At each incubation time and hormone, values with a different superscript letter are significantly different $(P<0.005)$.

Conversion of $\left[7(n)-{ }^{3} H\right]$ pregnenolone into progesterone and intermediary steroids

Text-figure 1 shows the mean conversion percentage of progesterone and the percentage of pregnenolone remaining after incubation of homogenates of preovulatory bovine follicles in the 
phases between the onset of oestrus and ovulation with the results of the statistical analysis. The production of progesterone showed a significant $(P<0.005)$ increase during incubation at phase 3 . The decrease during incubation of the percentage of pregnenolone remaining was significant $(P<0.05)$ at all phases, except at phase 2B. Follicles at phases $0,1,2 \mathrm{~A}$ and $2 \mathrm{~B}$ showed an appreciable production of $17 \alpha$-hydroxypregnenolone (Table 1). The unidentified steroid fraction (Table 1) was distributed over several areas on t.l.c.; no peaks were detected on the radioscans concurring with reference $17 \alpha$-hydroxyprogesterone. At phase 3 , when conversion into progesterone had increased sharply (Text-fig. 1), conversion into 17 $\alpha$-hydroxypregnenolone was significantly $(P<0.01)$ less than in the preceding phases. Two follicles which showed a high conversion percentage of progesterone ( 97.6 and $96.6 \%$ after 120 min incubation, respectively) did not produce detectable amounts of $17 \alpha$-hydroxypregnenolone. The one follicle collected shortly after ovulation showed a high conversion percentage of progesterone after $15,30,60$ and 120 min incubation (72.7, $87 \cdot 7,94 \cdot 7$ and $96.9 \%$ respectively), and the percentages of pregnenolone remaining were $25 \cdot 6,10 \cdot 4$, 2.6 and $0.6 \%$ respectively; the conversion percentage of $17 \alpha$-hydroxypregnenolone after $120 \mathrm{~min}$ incubation was $2 \cdot 46 \%$.

\section{Conversion of $\left[1,2,6,7(n)-{ }^{3} H\right]$ progesterone}

The conversion percentage of $17 \alpha$-hydroxyprogesterone and the percentage of progesterone remaining, after $120 \mathrm{~min}$ incubation with $\left[1,2,6,7(\mathrm{n})-{ }^{3} \mathrm{H}\right]$ progesterone of homogenates of preovulatory bovine follicles at phase 3 , were $22.4 \pm 2.4$ and $75.6 \pm 1.5 \%(n=3)$ respectively.

\section{Discussion}

Changes in progesterone-synthesizing ability of preovulatory bovine follicles relative to the preovulatory peak of $\mathrm{LH}$ were investigated in an in-vitro system using homogenates of the follicular wall, with tritiated pregnenolone as precursor. Although in this way the in-vivo intercellular contact and intracellular organization are lost and no data are available about endogenous pregnenolone concentrations and production, it is assumed that this system reflected in-vivo changes in progesterone-synthesizing ability during preovulatory follicular development.

Before the LH surge preovulatory bovine follicles were able to produce progesterone, but high conversion percentages were observed for $17 a$-hydroxypregnenolone and for the unidentified steroid fraction, which may have consisted of further intermediates of the $\Delta 5$-pathway. This is consistent with the preference for the $\Delta 5$-pathway in cow follicles as reported by Lacroix, Eechaute \& Leusen (1974). It is suggested that at phase 0 steroid synthesis of the preovulatory follicle is directed mainly to the production of oestradiol, as is reflected by the considerable oestradiol concentration in the fluid of follicles at the time, which is about 15 -fold higher than that of progesterone (Dieleman et al., 1983b). During phases 1,2A and 2B the moderate ability to produce progesterone was continued, and conversion of pregnenolone into the other steroids apparently prevailed. At phase 3, from $20 \mathrm{~h}$ after the LH peak until ovulation, however, a steep 4-fold increase of the conversion, into progesterone occurred. In 2 out of the 10 follicles collected at this phase pregnenolone was converted almost completely into progesterone alone; the one follicle collected shortly after ovulation showed a similar pattern. At phase 3 progesterone is probably the end-product, since conversion of this steroid into other steroids was limited in the presence of NADPH. Moreover, no conversion into $17 \alpha$-hydroxyprogesterone could be detected (i.e. conversion $<1 \%$ ) throughout preovulatory development. The high progesterone-synthesizing ability at phase 3 coincides with the previously reported 5-fold increase of the progesterone concentration in the follicular fluid (Dieleman et al., 1983b). This indicates that, in the cow, the high progesterone concentration in preovulatory follicles shortly before ovulation is not merely due to accumulation of progesterone into the fluid as supposed in the sheep (Murdoch \& Dunn, 1982), but to an increase of progesterone synthesis. In preovulatory follicles of sheep the progesterone concentration increases near the time 
of ovulation, but the increase is not reflected by the progesterone concentration in the ovarian venous blood (Murdoch \& Dunn, 1982). These authors speculated that this might be due to a reduced efflux of progesterone from the follicular fluid as a result of prostaglandin F-2 $\alpha$ acting as a vasoconstrictor.

The coincidence of the sharp increase in progesterone-synthesizing ability with the previously observed morphological luteinization of the granulosa cells (Dieleman et al., 1983b) suggests that the membrana granulosa is the major source of progesterone in preovulatory cow follicles at this stage of follicular development, as in the pig (Evans, Dobias, King \& Armstrong, 1981). The moderate conversion into progesterone during the phases before until $20 \mathrm{~h}$ after the $\mathrm{LH}$ peak possibly has to be attributed to the theca interna (Fortune \& Hansel, 1979a). The temporary increase of the progesterone concentration in the fluid of follicles at phase 1 (0-6 h after the LH peak; Dieleman et al., 1983b), however, was not reflected in the present in-vitro system. The lag between the termination of granulosa aromatizing ability at $14 \mathrm{~h}$ after the LH peak (Dieleman \& Blankenstein, 1984) and the onset of high progesterone production at $20 \mathrm{~h}$ may indicate that the $\Delta 5$-3 $\beta$-hydroxysteroid dehydrogenase, necessary to convert pregnenolone into progesterone, is newly synthesized or activated upon differentiation of the membrana granulosa into lutein cells. Contrary to this, the increase of progesterone formation in rat preovulatory follicles appears to be due to inhibition of $17 \alpha$-hydroxylase activity (Lieberman et al., 1975).

Explanted granulosa cells of cow follicles luteinize in about 2 days in culture, losing their aromatizing ability (Henderson \& Moon, 1979), and addition of oestradiol in a concentration similar to that observed in preovulatory cow follicles at oestrus prevents in-vitro luteinization (Fortune \& Hansel, 1979b). Despite this, it is supposed that luteinization in vivo in preovulatory cow follicles is caused by the preovulatory surge of $\mathrm{LH}$, since this process became apparent at about $20 \mathrm{~h}$ after the $\mathrm{LH}$ peak and about $14 \mathrm{~h}$ after the onset of the decrease of the oestradiol concentration in the fluid (Dieleman et al., 1983b), as opposed to the 2 days in vitro. It is not known whether the high concentration of follicle-stimulating hormone (FSH) observed in the fluid of cow follicles at phase 3 (Dieleman et al., 1983a) is also required to stimulate progesterone synthesis; in the rat (Wang \& Chan, 1982), FSH stimulates granulosa progesterone production in vitro. The function of the high progesterone production at the time is not well understood, but it may be involved in oocyte maturation (Kruip, Cran, Van Beneden \& Dieleman, 1983) and ovulatory processes (see Peters \& McNatty, 1980, for review).

The present results indicate that the preovulatory LH surge changes the preovulatory cow follicle from an oestradiol-producing gland at oestrus to one in which progesterone synthesis is dominant shortly before ovulation.

We thank Professor A. H. Willemse and Professor P. A. Voogt for reading the manuscript; Mrs H. T. M. van Tol and Mr A. V. P. van de Poll for technical assistance; and Mr W. Bes for drawing the figure.

\section{References}

Ainsworth, L., Tsang, B.K., Downey, B.R., Marcus, G.J. \& Armstrong, D. T. (1980) Interrelationships between follicular fluid steroid levels, gonadotrophic stimuli, and oocyte maturation during preovulatory development of porcine follicles. Biol. Reprod. 23, 621-627.

Dieleman, S.J. \& Blankenstein, D.M. (1984) Changes in oestrogen-synthesizing ability of preovulatory bovine follicles relative to the peak of LH. J. Reprod. Fert. 72, 487-494.

Dieleman, S.J., Bevers, M.M., Poortman, J. \& van Tol, H.T.M. (1983a) Steroid and pituitary hormone concentrations in the fluid of preovulatory bovine follicles relative to the peak of $\mathrm{LH}$ in the peripheral blood. J. Reprod. Fert. 69, 641-649.

Dieleman, S.J., Kruip, Th.A.M., Fontijne, P., de Jong, W.H.R. \& van der Weyden, G.C. (1983b) Changes in oestradiol, progesterone and testosterone concentrations in follicular fluid and in the micromorphology of preovulatory bovine follicles relative to the peak of luteinizing hormone. J. Endocr. 97, $31-42$.

Dufour, J., Whitmore, H.L., Ginther, O.J. \& Casida, 
L.E. (1972) Identification of the ovulating follicle by its size on different days of the estrous cycle in heifers. J. Anim. Sci. 34, 85-87.

Evans, G., Dobias, M., King, G.J. \& Armstrong, D.T. (1981) Estrogen, androgen, and progesterone biosynthesis by theca and granulosa of preovulatory follicles in the pig. Biol. Reprod. 25, 673-682.

Fortune, J.E. \& Hansel, W. (1979a) Effects of LH surge on steroid secretion by theca and granulosa cells of bovine preovulatory follicles. Biol. Reprod. 20, Suppl. 1,46, Abstr.

Fortune, J.E. \& Hansel, W. (1979b) The effects of $17 \beta$-estradiol on progesterone secretion by bovine theca and granulosa cells. Endocrinology 104, $1834-1838$.

Fritz, M.A. \& Sperofi, L. (1982) The endocrinology of the menstrual cycle: the interaction of folliculogenesis and endocrine mechanisms. Fert. Steril. 38, 509-529.

Henderson, K.M. \& Moon, Y.S. (1979) Luteinization of bovine granulosa cells and corpus luteum formation associated with loss of androgen-aromatizing ability. J. Reprod. Fert. 56, 89-97.

Kruip, Th.A.M. \& Dieleman, S.J. (1982) Macroscopic classification of bovine follicles and its validation by micromorphological and steroid biochemcial procedures. Reprod. Nutr. Dévelop. 22, 465-473.

Kruip, Th.A.M., Cran, D.G., Van Beneden, Th.H. \& Dieleman, S.J. (1983) Structural changes in bovine oocytes during final maturation in vivo. Gamete Res. 8, 29-47.
Lacroix, E., Eechaute, W. \& Leusen, I. (1974) The biosynthesis of estrogens by cow follicles. Steroids 23, 337-356.

Lieberman, M.E., Barnea, A., Bauminger, S., Tsafriri, A., Collins, W.P. \& Lindner, H.R. (1975) LH effect on the pattern of steroidogenesis in cultured Graafian follicles of the rat: dependence on macromolecular synthesis. Endocrinology 96, 1533-1542.

McNatty, K.P., Hunter, W.M., McNeilly, A.S. \& Sawers, R.S. (1975) Changes in the concentration of pituitary and steroid hormones in the follicular fluid of human Graafian follicles throughout the menstrual cycle. $J$. Endocr. 64, 555-571.

Murdoch, W.J. \& Dunn, T.G. (1982) Alterations in follicular steroid hormones during the preovulatory period in the ewe. Biol. Reprod. 27, 300-307.

Peters, H. \& McNatty, K.P. (1980) Ovulation. In The Ovary, pp. 75-84. Ed. C. A. Finn. Granada Publishing Ltd, London.

Scheffé, H. (1959) The Analysis of Variance. John Wiley, New York.

Szoltys, M. (1976) Progestagen dynamics in preovulatory follicles of rats. J. Reprod. Fert. 48, 397-398.

Wang, C. \& Chan, V. (1982) Divergent effects of prolactin on estrogen and progesterone production by granulosa cells of rat Graafian follicles. Endocrinology 110, 1085-1093.

Received 1 April 1985 